\title{
Characterization of Epstein-Barr Viral Strains in Parotid Gland Saliva and Peripheral Blood of Patients With Primary Sjögren's Syndrome and Healthy EBV Carriers
}

\author{
M.A.P. Oosterveer, H.M. Markusse, E.T. Lennette, J.Z. Zou, R.L.H. Bolhuis, and J.W. Gratama \\ Departments of Clinical and Tumor Immunology (M.A.P.O., R.L.H.B., J.W.G.) and Rheumatology (H.M.M.), Daniel \\ den Hoed Cancer Center, Rotterdam, the Netherlands; Virolab Inc., Berkeley, California (E.T.L.); and Department of \\ Virology, Karolinska Institute, Stockholm, Sweden (J.Z.Z.)
}

Increased Epstein-Barr virus (EBV) replication has been reported in the salivary and lacrimal glands in Sjögren's syndrome (SS). We studied whether or not certain EBV strains would occur preferentially in the peripheral blood and parotid gland saliva of $18 \mathrm{EBV}$-seropositive patients with primary Sjögren's syndrome (pSS) and 12 EBV-seropositive control persons. Transforming EBV was detected in the blood of 11 of $18(61 \%)$ pSS patients and 9 of 12 controls (75\%). Unexpectedly, neither transforming nor Raji-superinfecting EBV strains were detected in SS parotid saliva, whereas these EBV types were detected in control saliva in 7 and 8 cases, respectively $(P<0.001)$. Transforming EBV strains were further characterized by 'Ebnotyping,' i.e., analysis of the size spectrum of the viral antigens EBNA 1, 2, 3, and 6 in immunoblots of lymphoblastoid cell lines (LCL). Previous work has shown that a single EBV strain (Ebnotype) dominates the blood and oropharynx of healthy carriers and that unrelated individuals carry different EBV strains, reflecting the vast polymorphism of Ebnotypes in the general population. Two unexpected observations were made. First, an identical Ebnotype was detected in 4 unrelated individuals, i.e., in the blood of 1 pSS patient and in the saliva of 3 control persons. Second, carriage of 2 to 4 different Ebnotypes by a single individual was observed in 4 cases, i.e., in the blood of 1 pSS patient, and in the blood and saliva of 3 control persons. As only 1 control person had received a blood transfusion, it is suggested that (super)infection with exogenous EBV strains via salivary transmission and/or recombination of endogenous virions may have contributed to this situation.

(C) 1993 Wiley-Liss, Inc.

KEY WORDS: Epstein-Barr virus, Sjögren's syndrome, viral strains, virus detection, immunoblotting

\section{INTRODUCTION}

Epstein-Barr virus (EBV) is a ubiquitous herpesvirus that spreads through populations by salivary contact. EBV preferentially infects 2 cell types: the B lymphocytes, where the infection is largely nonproductive [Nilsson et al., 1971], and stratified squamous epithelia in which EBV replication occurs [Sixbey et al., 1984]. Intense replication of EBV in epithelial cells is accompanied by the presence of EBV deletion mutants [Patton et al., 1988; Sixbey et al., 1991]. Such deletions have a profound impact on the biological properties of the virus. The archetypal EBV biotype, B95.8, has been isolated from lymphocyte cultures and is capable to immortalize B lymphocytes into permanent lymphoblastoid cell lines (LCL) [Miller et al., 1974]. Such LCL carry EBV genomes persistently; they express the growth transformation-associated nuclear proteins EBNA 1 to 6 and the membrane-associated proteins LMP 1 and LMP 2 [Kieff and Liebowitz, 1990]. Among these proteins EBNA 2 plays a key role in lymphocyte transformation [Cohen et al., 1989]. EBNA 2 deletion variants, represented by the P3HR-1 strain, produce abortive infections without assembly of mature virions and can be detected by their ability to induce early antigens (EA) in the EBV-carrying Burkitt's lymphoma cell line Raji [Hinuma et al, 1967]. EBV strains may also be categorized into Type A or Type B based on the organization of their BamHI WYH and $\mathrm{E}$ gene regions. The differences between these 2 types arise from sequence divergence within the open reading frames encoding EBNA 2, 3, 4, and 6 [Adldinger et al., 1985; Rowe et al., 1989]. Type A EBV strains transform B lymphocytes efficiently, whereas Type B strains do so

Accepted for publication January 25, 1993.

Address reprint requests to J.W. Gratama, M.D., Department of Clinical and Tumor Immunology, Daniel den Hoed Cancer Center, P.O. Box 5201, 3008 AE Rotterdam, The Netherlands. 
poorly [Rickinson et al., 1987]. A wide variety of Type A and $B$ strains can be distinguished on the basis of size variations of EBNA 1 to 6 in immunoblots ('Ebnotyping') [Gratama et al., 1990a,b, 1992]. Coinfection with multiple EBV strains including $A$ and $B$ types is rare in healthy carriers but relatively frequent in immunodeficient patients such as human immunodeficiency virus (HIV)-infected individuals [Sixbey et al., 1989; Sculley et al., 1990] and bone marrow transplant recipients [Gratama et al., 1992].

Sjögren's syndrome (SS) is a systemic autoimmune disease characterized by the simultaneous presence of dryness of the mouth (xerostomia) and eyes (keratoconjunctivitis sicca) associated with lymphocytic infiltration of the salivary and lacrimal glands. The term 'secondary Sjögren's syndrome' is used when objective evidence of xerostomia and keratoconjunctivitis sicca is associated with an already well estabished autoimmune disease such as rheumatoid arthritis or systemic lupus erythematosus. Otherwise the disease is termed primary Sjögren's syndrome (pSS) [Moutsopoulos et al., 1980]. In salivary glands of SS patients, EBV DNA was detected in the nuclei of epithelial cells lining ducts and acini, which also expressed the replicative cycle EBV early antigen (EA) [Venables et al., 1989]. SS salivary glands contained increased levels of EBV DNA in comparison to normal salivary glands as detected by slot blot hybridization [Fox et al., 1986] and polymerase chain reaction (PCR) [Saito et al., 1989]. EBV was detected predominantly in the epithelial cells of SS glands rather than in the lymphocytic infiltrate [Fox et al., 1986; Schuurman et al., 1989; Venables et al., 1989; Mariette et al., 1991], in which activated T lymphocytes of the helper phenotype $\left(\mathrm{CD}^{+}, 4^{+}, 38^{+}, \mathrm{HLA}-\mathrm{DR}^{+}\right)$ predominated [Adamson et al., 1983]. These combined data indicate that EBV replication is increased in the glandular epithelia of SS patients.

We investigated whether or not EBV replicative activity in the parotid gland epithelia of pSS patients was associated with the occurrence of multiple EBV biotypes in salivary gland excretions. Therefore, we combined Ebnotyping studies of transforming EBV with EA-induction assays of Raji cells to detect Raji-superinfecting EBV.

\section{PATIENTS AND METHODS Patients}

Peripheral blood and parotid salivary samples were obtained from 18 patients diagnosed with pSS (all women; mean age 60 years [SD 12 years]; referred to as $\mathrm{P} 1$ to $\mathrm{P} 18$ ) and 12 control persons (all women; mean age 60 years [SD 13 years]; referred to as C19 to C30). All patients and control persons were IgG seropositive for the viral capsid antigen of EBV. The patients met all of the following criteria for $\mathrm{pSS}: 1$ ) subjective evidence of dryness of the eyes and mouth; 2 ) at least 2 positive diagnostic tests for keratoconjunctivitis sicca [Manthorpe et al., 1986]; 3) more than 1 focus of 50 or greater mononuclear cells per $4 \mathrm{sq} \mathrm{mm}$ salivary gland tissue from the lower lip and/or an abnormal parotid gland sialography; and 4) the presence of serum rheumatoid factor and/or antinuclear antibodies and/or anti-SS-A and/or anti-SS-B antibodies. None of the patients fulfilled the established criteria for another connective tissue disease. The control persons were seen for noninflammatory rheumatoid conditions at the Outpatient Rheumatology Clinic. Secretion of parotid saliva was stimulated at least 1 hour after a meal by application of citric acid under the tongue every 30 seconds over 10 minutes. Parotid saliva was collected with a cup placed over the opening of Stensen's duct preventing the admixture of citric acid and saliva from other sources. From 8 patients, additional tongue scrapings and mouthwashes were obtained prior to citric acid stimulation. Tongue scrapings were resuspended in $10 \mathrm{ml}$ RPMI 1640 medium. Mouthwashes were obtained by gargling for $1 \mathrm{~min}$ with $10 \mathrm{ml}$ RPMI 1640 medium. Prior to setting up assays to detect transforming EBV (on the same or following day), bacteria and debris were removed from all oropharyngeal specimens and $10 \%$ (v/v) fetal calf serum (FCS) was added. The remainders of the oropharyngeal specimens were cryopreserved at $-80^{\circ} \mathrm{C}$ until their use in the EA induction and PCR assays.

\section{Detection of Transforming EBV}

Peripheral blood mononuclear cells (PBMC) were isolated from heparinized blood samples and cultured in 96-well flat-bottomed microtiter plates for 8 to 12 weeks to obtain LCL [Gratama et al., 1990b]. Within 1 week after initiation of the cultures, 100,000 fresh cord blood mononuclear cells were added to each well in order to rescue $\mathrm{EBV}$ released from virus-carrying cells [Lewin et al., 1987]. For lymphocyte transformation assays by oropharyngeal specimens, 12 million cord blood mononuclear cells were incubated for 3 to 6 hours with undiluted $3 \mathrm{ml}$ aliquots of the mouthwashes or tongue scrapings, and with $3 \mathrm{ml}$ aliquots of 1:10 dilutions of parotid gland salivary samples in RPMI $1640+10 \%$ FCS. Thereafter, the cells were washed and cultured for 8 to 12 weeks in 96-well flat-bottomed microtiter plates [Gratama et al., 1990b]. In order to allow the detection of multiple strains of transforming EBV from a single specimen by immunoblotting (see below), wells with growing cells were harvested and expanded individually from these 2 types of cultures.

\section{Detection of Raji-Superinfecting EBV}

Oropharyngeal specimens were diluted 1:2 in RPMI $1640+10 \%$ FCS, sonicated for 10 seconds to release intracellular virions and filtered through $0.2 \mu \mathrm{m}$ filters before inoculation. Exponentially growing, EA-D negative Raji cells were resuspended to $0.5 \times 10^{6}$ cells in 0.5 ml RPMI $1640+10 \%$ FCS per flat bottom centrifuge tube, followed by addition of $0.5 \mathrm{ml}$ of the filtered sample and centrifugation at $4,000 \mathrm{~g}$ at $35^{\circ} \mathrm{C}$ for 40 minutes After resuspending the cells, $2.0 \mathrm{ml}$ RPMI $1640+10 \%$ FCS were added to each tube, followed by incubation for 96 hours. Thereafter, the cells were spun down, concentrated to $1 / 100$ th of the original volume and spread onto 6 coverslips ( $50 \mathrm{sq} \mathrm{mm}$ each). The cells were then air dried, fixed with acetone and stained with a human 
TABLE I. EBV Detection in pSS Patients and Control Persons

\begin{tabular}{llcc}
\hline Sampling site & EBV detection assay & pSS patients & Control persons \\
\hline Peripheral blood & Transforming & $11 / 18(61 \%)$ & $9 / 12(75 \%)$ \\
Stensen's duct & Transforming & $0 / 17$ & $7 / 12(58 \%)$ \\
& Raji-superinfecting & $0 / 17$ & $8 / 12(67 \%)$ \\
Tongue & Transforming & $0 / 8$ & ND $^{\mathrm{a}}$ \\
& Raji-superinfecting & $1 / 8(13 \%)$ & ND \\
Mouthwash & PCR & $1 / 8(13 \%)$ & ND \\
& Transforming & $0 / 8$ & ND \\
& Raji-superinfecting & $0 / 8$ & ND \\
\hline
\end{tabular}

${ }^{a} \mathrm{ND}$, not done.

serum positive for anti-EA-D antibodies but negative for EBNA antibodies. The number of EA-D + cells were counted in quadruplicates. Uninfected Raji control cultures, processed in parallel, contained fewer than 2 EA-D + cells per cover slip. A culture yielding 5 times or more EA-D + cells than the uninfected control was considered positive for Raji-superinfecting EBV strains.

\section{PCR}

Primers and Taq polymerase were obtained from Scandinavian Gene Synthesis Systems (Enköping, Sweden) for use in a nested PCR. The sequence of the primers was derived from a conserved part of the EBNA 1-coding BKRF1 gene outside the Gly-Ala repeat that varies between wild-type EBV strains [Hennessy and Kieff, 1983]. The sequence of the outer primers, i.e., 5'AAGGAGGGTGGTTTGGAAAG3' and 5'AGACAATGGACTCCCTTAGC3', corresponded to B95.8 coordinates 109,332 to 109,351 and 109,609 to 109,628 , respectively. The sequence of the inner primers, i.e., 5'ATCGTGGTCAAGGAGGTTCC3' and 5'ACTCAATGGTGTAAGACGAC3' corresponded to B95.8 coordinates 109,353 to 109,372 and 109,542 to 109,561 , respectively [Baer et al., 1984]. DNA was prepared by adding $0.1 \mathrm{ml}$ lysis buffer to $0.1 \mathrm{ml}$ oral specimen, followed by a 60 -minute incubation at $55^{\circ} \mathrm{C}$ and a subsequent 15 -minute incubation at $95^{\circ} \mathrm{C}$. Ten $\mu l$ of the lysates were first amplified for 20 cycles by the outer primer pair, followed by amplification in a nested PCR for 30 cycles using the inner primer pair. The final PCR products were visualized by electrophoresis in a $2 \%$ agarose gel, ethidium bromide staining, and photography using a Polaroid camera. A 170-bp fragment was considered specific for EBV. The B95.8-transformed LCL ZV18 was used as positive control and the EBVnegative cell lines BL41 and HSB2 were used as negative controls.

\section{Immunoblotting}

Aliquots corresponding to 1 million LCL dissolved in electrophoresis sample buffer were loaded per lane for electrophoresis in gels containing $7.5 \%$ polyacrylamide and sodium dodecyl sulfate. The electroblotting procedure and the immunological detection of the EBNA proteins on the nitrocellulose filters was performed as described previously [Gratama et al., 1990b].
For the characterization of wild-type EBV strains on the basis of their different patterns of size of their nuclear antigens EBNA 1, 2, 3, 4, and 6 ('Ebnotyping'), serum from a patient with chronic lymphocytic leukemia [Lewin et al., 1988] was used at a 1:20 dilution for the detection of EBNA 1, 2, 3, 4, and 6. This serum also reacted with EBNA 5, seen as multiple weak bands in the 22 to $90 \mathrm{kD}$ region. EBNA 1 and 2 were allocated to their specific bands using monospecific reagents. For EBNA 1, serum JF absorbed with Ramos cells was used, and for EBNA 2, monoclonal antibody (mAb) PE2 [Young et al., 1989]. Serum MSt, concraining EBNA and EBNA 6 antibodies, was used for the selective detection of EBNA 6. The EBNA 1 antibodies did not interfere with the detection of EBNA 6 since the estimated mouthwash (MW) of the EBNA 1 protein never exceeded $100 \mathrm{kD}$ and the MW of EBNA 6 ranged between 140 and $180 \mathrm{kD}$. The PE2 and MSt reagents were kind gifts of Dr. M. Rowe (Birmingham, UK). LMP 1 was detected using the S12 $\mathrm{mAb}$ (a kind gift of Dr. D. Thorley-Lawson, Boston, MA).

For the detection of EBNA antibodies in patient sera with high-titered BJA-B antibodies, a panel of 2 EBVnegative Burkitt's lymphoma cell lines (BJA-B and Ramos), 3 LCL-carrying Type A EBV (TC 6 DOU, TC 287 DON and TC 362 REN), and 2 LCL-carrying Type B EBV (TC $3 \mathrm{KOE}$ and TC 287 VOS) were used. The size of the EBNA proteins of these LCL had been determined using monospecific sera (see above and Gratama et al. [1990a]). The use of these cell lines allowed the distinction between serological reactivities with the EBNA 1, 2, 3, and 6 proteins and EBV-nonspecific reactivities in most cases. The reactivities of the sera were scored on the basis of the intensity of each EBNA band, ranging from - (negative) to ++++ (strongly positive). The reactivities of sera with Type A versus Type B EBV strains could also be determined, since large antigenic differences exist between the EBNA 2 and 6 proteins of both types of EBV strains [Rowe et al., 1989].

\section{RESULTS EBV Detection}

pSS patients and control persons showed similar frequencies of spontaneously outgrowing LCL from the blood: 11 of $18(61 \%)$ pSS patients and 9 of $12(75 \%)$ 
TABLE II. Characterization of Transforming EBV Strains

\begin{tabular}{|c|c|c|c|c|}
\hline \multirow{2}{*}{$\begin{array}{l}\text { Patient } \\
\text { or control } \\
\text { person }^{a}\end{array}$} & \multicolumn{2}{|c|}{ Assay for transforming EBV } & \multirow{2}{*}{$\begin{array}{c}\text { Expansion } \\
\text { \# LCL } \\
\text { established }^{c}\end{array}$} & \multirow{2}{*}{$\begin{array}{c}\text { Immunoblotting } \\
\text { Type and \# of } \\
\text { EBV strains }\end{array}$} \\
\hline & $\begin{array}{l}\text { \# wells } \\
\text { plated }\end{array}$ & $\begin{array}{l}\text { \# wells w/ } \\
\text { outgrowth }^{\text {b }}\end{array}$ & & \\
\hline P1 (PB) & 60 & $17(28 \%)$ & $2(12 \%)$ & 1 A-strain \\
\hline $\mathrm{P} 2(\mathrm{~PB})$ & 60 & $3(5 \%)$ & 0 & \\
\hline $\mathrm{P} 3$ (PB) & 60 & $2(3 \%)$ & 0 & \\
\hline $\mathrm{P} 4(\mathrm{~PB})$ & 60 & $16(27 \%)$ & $1(6 \%)$ & 1 A-strain \\
\hline P5 (PB) & 60 & $4(7 \%)$ & 0 & \\
\hline P8 (PB) & 120 & $54(45 \%)$ & $7(13 \%)$ & 2 A-strains \\
\hline $\mathrm{P9}$ (PB) & 60 & $1(2 \%)$ & 0 & \\
\hline P10 (PB) & 120 & $14(12 \%)$ & $8(57 \%)$ & 1 A-strain \\
\hline P12 (PB) & 60 & $5(8 \%)$ & 0 & \\
\hline P14 (PB) & 60 & $3(5 \%)$ & $2(67 \%)$ & 1 A-strain \\
\hline P17 (PB) & 60 & $9(15 \%)$ & 0 & \\
\hline C19 (PB) & 60 & $3(5 \%)$ & $1(33 \%)$ & 1 A-strain \\
\hline $\mathrm{C} 20$ (PB) & 60 & $4(7 \%)$ & 0 & 1 A-strain \\
\hline $\mathrm{C} 20$ (SA) & 60 & $3(5 \%)$ & $1(33 \%)$ & \\
\hline $\mathrm{C} 21(\mathrm{SA})$ & 60 & $2(3 \%)$ & $1(50 \%)$ & 1 A-strain \\
\hline $\mathrm{C} 22(\mathrm{~PB})$ & 60 & $58(97 \%)$ & $24(41 \%)$ & 1 A-strain \\
\hline $\mathrm{C} 22(\mathrm{SA})$ & 60 & $2(3 \%)$ & 0 & \\
\hline $\mathrm{C} 24(\mathrm{~PB})$ & 60 & $4(7 \%)$ & $3(75 \%)$ & 3 A-strains \\
\hline $\mathrm{C} 24(\mathrm{SA})$ & 60 & $2(3 \%)$ & 0 & \\
\hline C25 (PB) & 60 & $16(27 \%)$ & $8(50 \%)$ & 4 A-strains \\
\hline $\mathrm{C} 25(\mathrm{SA})$ & 60 & $2(3 \%)$ & $1(50 \%)$ & \\
\hline $\mathrm{C} 26(\mathrm{~PB})$ & 60 & $2(3 \%)$ & $2(100 \%)$ & 1 A-strain \\
\hline $\mathrm{C} 27(\mathrm{~PB})$ & 60 & $1(2 \%)$ & $1(100 \%)$ & 2 A-strains \\
\hline C27 (SA) & 60 & $5(8 \%)$ & $1(13 \%)$ & \\
\hline $\mathrm{C} 29(\mathrm{~PB})$ & 60 & $13(22 \%)$ & $7(54 \%)$ & 1 A-strain \\
\hline $\mathrm{C} 30$ (PB) & 60 & $3(5 \%)$ & $2(67 \%)$ & 1 A-strain \\
\hline $\mathrm{C} 30(\mathrm{SA})$ & 60 & $3(5 \%)$ & 0 & \\
\hline
\end{tabular}

aSampling site between brackets (PB, peripheral blood; SA, parotid saliva).

bBetween parentheses: percentage of wells showing outgrowth (expressed as fraction of the number of plated wells).

${ }^{c}$ Between parentheses: percentage of wells from which long-term growing LCL could be established (expressed as fraction of the number of wells showing outgrowth).

controls (Table I). The proportion of wells showing outgrowth per positive culture was also similar in both groups (Table II): pSS patients, median 8\% (range 2-45\%); control persons, median 7\% (range 2-97\%). In contrast, neither transforming nor Raji-superinfecting EBV was detected in the parotid saliva of any of 17 pSS patients, whereas transforming EBV was detected in 7 , and Raji-superinfecting EBV in 8 of 12 control persons (Table I; $P<0.001$ in both instances; 2-sided Fisher's exact test). The assays for transforming and Raji-superinfecting EBV in parotid saliva of pSS patients and control persons showed significant concordance (Table I): 6 of 7 samples positive for transforming EBV were also positive for Raji-superinfecting EBV, whilst 20 of 22 samples negative for transforming EBV also yielded negative results for Raji-superinfecting EBV $(P<0.001)$. We then investigated whether or not EBV shedding from other sites in the oropharyngeal cavity of the pSS patients was also impaired. Parallel EBV detection assays were set up from tongue scrapings, mouthwashes, and parotid salivary samplings in 8 patients. Again, all assays were negative, with the exception of a positive culture of Raji-superinfecting EBV from the tongue-scraping of P15. Finally, EBV detection was attempted by PCR in 8 tongue scrapings and 5 mouthwashes. The PCR results of the tongue scrapings were completely concordant with those of the Raji-superinfection assays: only P15's tongue-scraping was positive. The PCR on the 5 mouthwashes was negative with the exception of a positive result on the mouthwash of P8.

\section{EBV Serotyping}

The unexpected low frequency of detection of transforming $\mathrm{EBV}$ in the pSS patients may be due to their preferential carriage of Type B EBV strains which are poorly transforming [Rickinson et al., 1987]. We investigated this possibility by extrapolating the carrier status of Type B EBV strains from the detection on immunoblots of an EBNA antibody pattern specific for Type B EBV strains. Immunoblots reacting with the $18 \mathrm{pSS}$ sera were readily interpretable in spite of EBV-nonspecific reactivities. Example immunoblots of sera from 2 pSS patients ( $\mathrm{P} 8$ and $\mathrm{P} 12$ ), both reactive with the EBVnegative cell lines BJA-B and Ramos, are shown in Figure 1. The P8 serum contained antibodies to Type A but not Type B EBV, as evidenced by the selective recoginition of EBNA 2 and 6 of the LCL-carrying Type A virus. Patient 12 had antibodies to Type $B$ but not Type A EBV, as evidenced by: a) the stronger reactivity with Type B as compared to Type A EBNA 2; b) the nonreactivity with Type A EBNA 6; and c) the recognition of 1 to 4 bands between 140 and $180 \mathrm{kD}$ in Type B EBVcarrying LCL. Using these criteria, 11 of the $18 \mathrm{pSS}$ sera were reactive with Type A and 4 with Type B EBV. The EBNA 2 and 6 antibody titers in the remaining 3 


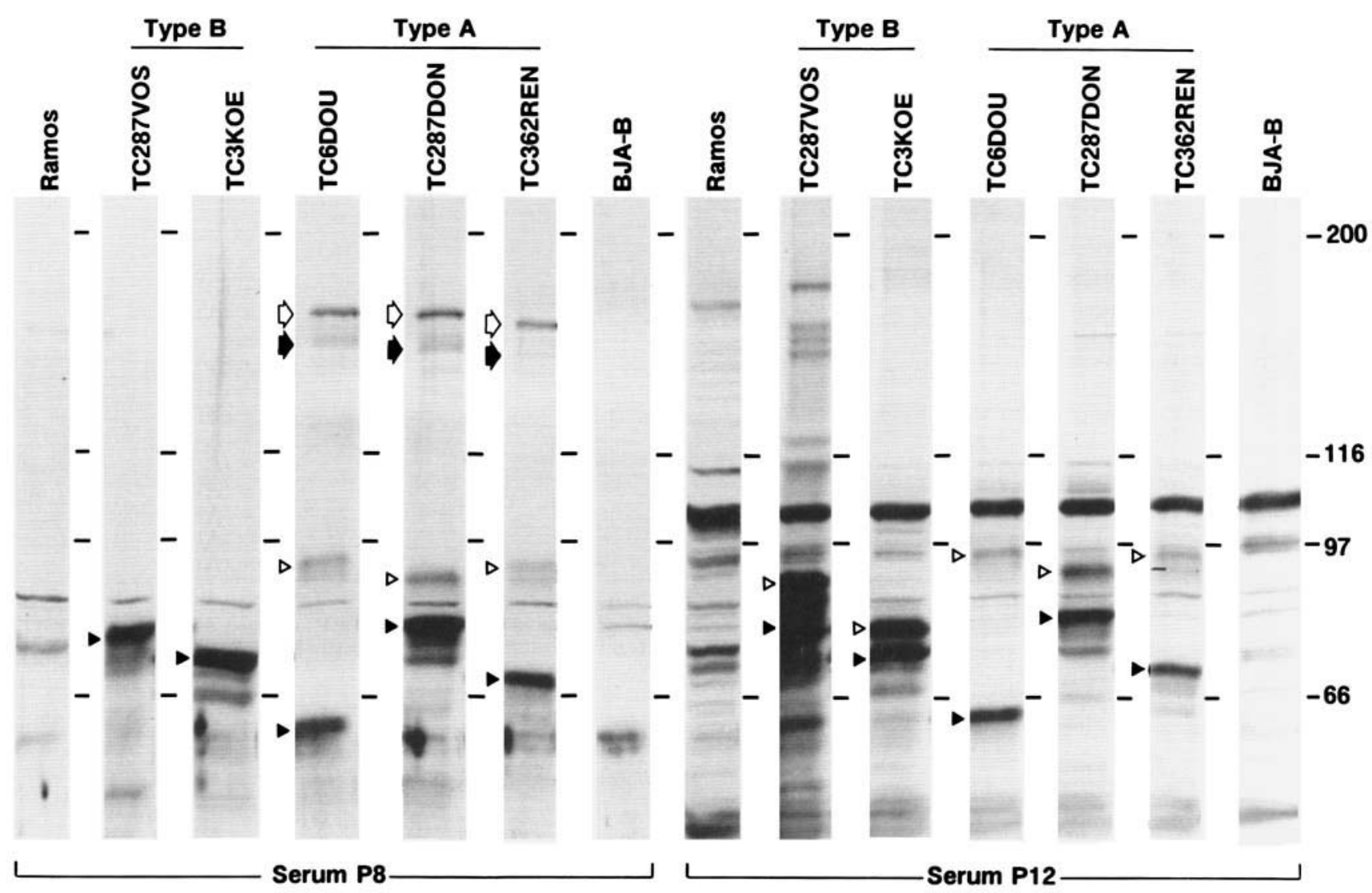

Fig. 1. Immunoblot probed with the sera from patients P8 (left panel) and P12 (right panel). Numbers in the middle indicate $\mathrm{MW}$ in $\mathrm{kD}$. The EBV-negative BJA-B and Ramos cell lines were used as negative controls. EBNA 1 (indicated in the figure as ), $2(\Delta), 3(\downarrow)$ and $6(0)$ were assigned to their corresponding bands after probing with monospecific antisera (see Patients and Methods and Gratama et al. $[1990 \mathrm{~b})$. The P8 serum was reactive with EBNA 1, 2, 3, and 6 of the

sera were too low to allow the assessment of their reactivity patterns (Table III).

\section{Characterization of Wild-Type Transforming EBV Strains}

Wells with growing cells were harvested separately, followed by expansion of the resulting LCL to allow Ebnotyping. LCL were established with significantly lower efficiency from the blood of the pSS patients than from that of the control persons (Table II): LCL were successfully established from only a minority of wells with growing cells (median 0\%; range 0-67\%) in the pSS patients versus $54 \%$ (range $0-100 \%$ ) in the control persons ( $P=0.02$ with Wilcoxon's 2 -sample test).

LCL from the blood of 5 pSS patients and 8 control persons, and from the saliva of 4 control persons were expanded sufficiently to allow Ebnotyping (Table II and Fig. 2). All LCL carried Type A EBV strains. No LCL was established from any of the 4 patients with Type B EBNA antibodies (P6, P7, P11, and P12). Thus, our culture system may have selected against Type B EBV strains. Two unexpected observations were made. First,
Type A strains and only with EBNA 1 of the Type B strains. The P12 serum was a) strongly reactive with Type B EBNA 2 and showed weaker reactivity with Type A EBNA 2 ; b) nonreactive with Type A EBNA 3 and 6 , but recognized 4 bands in the $140-180 \mathrm{kD}$ range in TC 287 VOS (Type B); and c) similarly reactive with Type A and B EBNA 1 proteins.

a single EBV strain was shared by 4 unrelated individuals: the Ebnotype expressed by LCL G8 derived from the blood of P8 was also detected in LCLs G8, D11, and $\mathrm{B} 10$ derived from the saliva of $\mathrm{C} 20, \mathrm{C} 21$, and $\mathrm{C} 25$, respectively (Fig. 2). Second, simultaneous carriage of 2 to 4 Type A EBV strains was observed in 4 cases (P8, C24, C25, and C27; Table IV and Fig. 2). The MW of EBNA 1, 2, 6, and LMP 1 were estimated after immunoblotting with monospecific reagents as set out in Table IV. The 2 Ebnotypes identified in P8 and C27 differed in all 4 proteins in both cases. Three Ebnotypes were identified in C24. LCL E10 expressed an Ebnotype that differed only in EBNA 6 from that of LCL D10, whilst the Ebnotype of LCL F7 differed in all 4 proteins from D10, but its EBNA 6 was similar to that of E10. $\mathrm{C} 25$, the only individual with a positive blood transfusion history, showed the largest heterogeneity in Ebnotypes. Six of the 8 LCL derived from her peripheral blood carried the G6 Ebnotype. The remaining $2 \mathrm{LCL}$ shared only a single protein with G6, as did the LCL established from her parotid saliva culture: EBNA 2 of LCL D9, and LMP 1 of B5 and B10 were of the same size as the respective proteins of LCL G6. 
TABLE III. Detection of EBNA Antibodies in Sera From pSS Patients by Immunoblotting*

\begin{tabular}{|c|c|c|c|c|c|}
\hline Patient & EBNA 1 & EBNA 2A & EBNA 2B & EBNA 3 & EBNA 6 \\
\hline 1 & ++++ & $?$ & - & + & $++(\mathrm{A})$ \\
\hline 2 (act) & ++++ & + & - & + & $+(\mathrm{A})$ \\
\hline 3 (act) & +++ & $(+)$ & - & - & $+(\mathrm{A})$ \\
\hline 4 & +++ & + & - & - & - \\
\hline 5 & ++++ & + & - & - & - \\
\hline 6 & $+t+t$ & $(+)$ & + & t & $+(\mathrm{B})$ \\
\hline 7 & ++++ & + & ++ & + & $+(\mathrm{B})$ \\
\hline 8 (act) & ++++ & ++ & - & + & $+(\mathrm{A})$ \\
\hline 9 & ++++ & + & - & - & - \\
\hline 10 & ++++ & +++ & - & - & $++(\mathrm{A})$ \\
\hline 11 & ++++ & + & ++ & - & ++ (B) \\
\hline 12 & ++++ & + & $+t$ & - & +++ (B) \\
\hline 13 & ++++ & ++ & - & + & $+++(\mathrm{A})$ \\
\hline 14 & ++++ & ++ & - & + & +++ (A) \\
\hline 15 & ++++ & $+t$ & -. & - & $++(\mathrm{A})$ \\
\hline 16 & ++++ & $+t$ & - & +++ & $+++(\mathrm{A})$ \\
\hline 17 & +++ & ++ & - & - & $++(\mathrm{A})$ \\
\hline 18 (act) & + & ++ & - & - & $+(\mathrm{A})$ \\
\hline
\end{tabular}

*Reactivities of the sera were scored on the basis of the intensity of each EBNA band, ranging from (negative) to ++++ (strongly positive). (act), serological evidence of chronic active EBV infection as indicated by the presence of IgA VCA antibodies, high titers (i.e., >1280) of IgG VCA antibodies, and/or the presence of any type of EA antibodies. (A) or (B), reactive with LCL carrying Type A or B EBV strains, respectively.

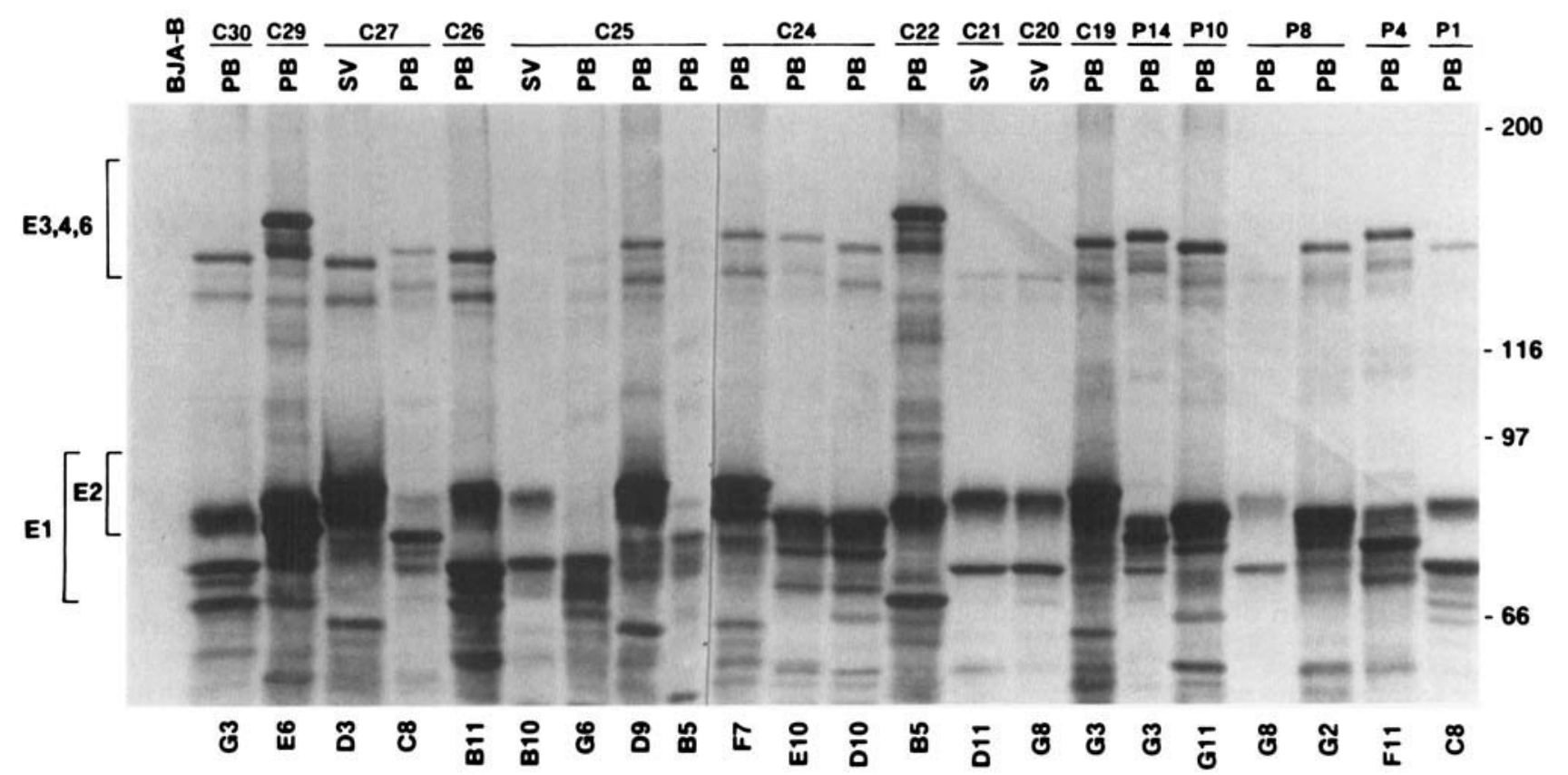

Fig. 2. Immunoblots probed with the polyspecific PG serum [Lewin et al., 1988]. Numbers on the right of each blot indicate MW in kD. The origin of the LCL (i.e., patient [P] or control [C]; peripheral blood [PB] or saliva [SV]) are indicated above the lanes. BJA-B was used as

\section{DISCUSSION}

Unexpectedly, the pSS patients distinguished themselves from the control persons in the absence of transforming and Raji-superinfecting EBV in their parotid gland saliva. Additional samplings from tongue and mouthwash were also negative with two exceptions. The latter result is clearly at variance with that of Miyasaka et al. [1989] who isolated transforming EBV negative control. Multiple LCL from a single individual are identified by their microtiter plate well numbers. All EBV strains were of Type A. They were all different with the exception of P8 PB[G8] which was identical to C20 SV, C21 SV, and C25 SV. E, EBNA.

from the mouthwashes of 25 of 29 patients. We have no other explanation for the difference between our results and those of Miyasaka et al. [1989] other than patient selection. The absence of transforming activity and the almost complete absence of Raji-superinfecting activity may reflect very low or absent EBV concentrations in the oral specimens of our patients. This contention is supported by the result that 11 of the 12 oral specimens 
TABLE IV. Multiple EBV Strains Within Single Individuals*

\begin{tabular}{lcccccc}
\hline Individual & Source & Well code & EBNA 1 & EBNA 2 & EBNA 6 & LMP 1 \\
\hline P8 & PB & G2 & $87^{\text {b }}$ & 85 & 146 & 57 \\
P8 & PB & G8 & 78 & 90 & - & 62 \\
C24 & PB & D10 & 85 & 86 & 144 & 66 \\
C24 & PB & E10 & 85 & 86 & 149 & 66 \\
C24 & PB & F7 & 92 & 90 & 149 & 64 \\
C25 & PB & B5 & 83 & 90 & 157 & 62 \\
C25 & PB & D9 & 91 & 88 & 148 & 65 \\
C25 & PB & G6 & 79 & 88 & 145 & 62 \\
C25 & SV & B10 & 78 & 90 & - & 62 \\
C27 & PB & C8 & 83 & 89 & 146 & 60 \\
C27 & SV & D3 & 91 & 88 & 143 & 63 \\
\hline
\end{tabular}

*PB, peripheral blood; SV, saliva.

aThe same Ebnotype was observed in 5 additional LCL obtained from the peripheral blood. ${ }^{b}$ Estimated MW in $\mathrm{kD}$.

"The same Ebnotype was observed in 6 additional LCL obtained from the peripheral blood.

that were negative for transforming or Raji-superinfecting activity were also PCR negative; the PCR used has a detection limit of $10 \mathrm{EBV}$ genome copies [I. Ernberg, personal communication]. An alternative explanation would be the generation of defective EBV particles with deletions in the BKRF1 template of our PCR.

The spectrum of Type A EBV strains that could be characterized on the basis of outgrowing LCL is most likely an underestimate of the variety of EBV strains carried by the patients and control persons. Establishment of permanently growing LCL was particularly difficult from the peripheral blood cultures of pSS patients and from the salivary cultures of the control persons. First, Type B EBV strains, known to have poor transforming capability [Rickinson, et al., 1987], may have been involved in these cases. We investigated this possibility by following the approach of Sculley et al. [1990] who extrapolated the carrier status of Type B EBV strains from the presence of Type B EBNA 2 antibodies. Indeed, 4 of 18 SS patients with Type B EBNA 2 antibodies were identified; from none of them could permanently growing LCL be established. Second, EBV strains with EA-inducing capability may be prevalent in parotid saliva. This contention is supported by the relatively high frequency of detection of EA-inducing virus ( 8 of 12 control persons) as compared to the establishment of permanently growing LCL from salivary cultures ( 4 of 12 control persons).

Although the spectrum of characterized EBV strains is probably skewed by the type of virus isolation procedure, i.e., B lymphocyte transformation, 2 interesting observations were made. First, 4 unrelated individuals shared one particular EBV strain. This strain was isolated from the saliva of control persons C20, C21, and $\mathrm{C} 25$, and was present in 1 of the $7 \mathrm{LCL}$ derived from Patient P8's blood. The sharing of identical EBV strains by unrelated individuals has not been observed in our previous studies on more than 40 EBV carriers [Gratama et al., 1990a,b; 1992]. However, these studies were based on EBV isolations from peripheral blood and mouthwash samples and did not include selective samplings from the parotid gland. The present observation may be explained by preferential homing of the shared EBV strain in the salivary gland epithelium and its presence in the B lymphocyte compartment as a minority strain. Interestingly, Niedobitek et al. [1991] detected an identical $66 \mathrm{kD}$ EBNA 1 band in immunoblots of 14 specimens derived from oral hairy leukoplakia lesions. Our data and those of Niedobitek et al. [1991] suggest that certain EBV strains are tropic for epithelial cell types, in analogy with the organ-specific selection of variants of murine chronic lymphocytic choriomeningitis virus infection [Ahmed and Oldstone, 1988].

Second, 4 individuals carried multiple Type A strains. Previous work [Yao et al., 1991; Gratama et al., 1992] has shown the dominance of a single transforming EBV strain in healthy virus carriers. Multiple transforming EBV strains were encountered in some recipients of bone marrow allografts. Two patterns of multiple EBV strain carriage were observed: a) coexistence of a Type A and a Type B EBV strain; and b) coexistence of multiple minority strains that differed from the predominant strain in only a single protein, i.e., EBNA 1 [Gratama et al., 1992]. The coexistence of Type A and B EBV strains has also been documented by PCR in the oropharynx of patients infected with the human immunodeficiency virus and, less frequently, healthy EBV carriers [Morgan et al., 1979; Sixbey et al., 1989]. The present study adds 2 new patterns: a) coexistence of 2-4 Type A strains differing in at least 2 of the following proteins: EBNA 1, EBNA 2, EBNA 6, and LMP 1 (patient P8 and control persons C24, C25, and C27); and b) coexistence of a 'variant' Type A strain differing only in EBNA 3, 4, and 6 (cf., the E10 and D10 isolates of control person $\mathrm{C} 24$ ).

One explanation for the coexistence of multiple EBV strains within a single individual would be (super)infection with exogenous strains, either via cell-borne virus (through blood transfusions, bone marrow or organ allografts), or via cell-free virions (through salivary contacts). As only one of the four carriers of multiple EBV strains, C25, had received blood transfusions, we suggest that superinfection with exogenous EBV strains is also possible via salivary transmission. Alternatively, EBV strain diversity may be generated by recombination between linear DNA molecules during virus replication. Such recombinations would affect the 
length of repeat sequences, which are present in all EBNA coding genes [Baer et al., 1984]; for instance, the size of EBNA 1 has been shown to correlate positively with the length of the coding sequence for the EBNA 1 Gly-Ala repeat [Hennessy and Kieff, 1983], and that of EBNA 6 with the length of a $(\mathbf{n} \times 39)$ nucleotide repeat [Falk et al., in preparation]. EBV replicates predominantly in epithelial cells but, to some extent, also in the lymphocytic compartment [Rowe et al., 1991]. If exogenous or recombinant virions account for the heterogeneity of EBV carried by the lymphocytes of a single individual, such virions would have to gain access to the long-term EBV reservoir by transforming lymphocytes in spite of EBV-specific immune surveillance.

\section{ACKNOWLEDGMENTS}

This work has been supported in part by grants from the Ank van Vlissingen Foundation (The Netherlands) and the Swedish Cancer Society. J.W. Gratama is a fellow of the Royal Dutch Academy of Arts and Sciences.

\section{LITERATURE CITED}

Adamson TC III, Fox RI, Frisman DM, Howell FV (1983): Immunohistologic analysis of lymphoid infiltrates in primary Sjogren's syndrome using monoclonal antibodies. Journal of Immunology 130:203-208.

Adldinger HK, Delius H, Freese UK, Clark J, Bornkamm GW (1985): A putative transforming gene of Jijoye virus differs from that of Epstein-Barr virus prototypes. Virology 141:221-228.

Ahmed R, Oldstone MBA (1988): Organ-specific selection of viral variants during chronic infection. Journal of Experimental Medicine 167:1719-1724.

Baer R, Bankier AT, Biggin MD, Deininger PL, Farrell PJ, Gibson TJ, Hatfull G, Hudson GSM, Satchwell SC, Seguin C, Tuffnell PS, Barrell BG (1984): DNA sequence and expression of the B95.8 Epstein-Barr virus genome. Nature 310:207-211.

Cohen JI, Wang F, Mannick J, Kieff E (1989): Epstein-Barr virus nuclear protein 2 is a key determinant of lymphocyte transformation. Proceedings of the National Academy of Science USA 86:9558-9562.

Fox RI, Pearson G, Vaughan JH (1986): Detection of Epstein-Barr virus-associated antigens and DNA in salivary gland biopsies from patients with Sjögren's syndrome. Journal of Immunology 137:3162-3168.

Gratama JW, Lennette ET, Lönnqvist B, Oosterveer MAP, Klein G, Ringdén O, Ernberg I (1992): Detection of multiple Epstein-Barr viral strains in allogeneic bone marrow transplant recipients. Journal of Medical Virology 37:39-47.

Gratama JW, Oosterveer MAP, Klein G, Ernberg I (1990a): EBNA size polymorphism can be used to trace Epstein-Barr virus spread within families. Journal of Virology 64:4703-4708.

Gratama JW, Oosterveer MAP, Lepoutre JMM, Van Rood JJ, Zwaan FE, Vossen JMJJ, Kapsenberg JG, Richel D, Klein G, Ernberg I (1990b): Serological and molecular studies of Epstein-Barr virus infection in allogeneic marrow graft recipients. Transplantation 49:725-730.

Hennessy K, Kieff E (1983): One of two Epstein-Barr virus nuclear antigens contains a glycine-alanine copolymer domain. Proceedings of the National Academy of Science USA 80:5665-5669.

Hinuma Y, Konn M, Yamaguchi J, Wudarski DJ, Blakeslee JR, Grace JT Jr (1967): Immunofluorescence and herpes-type virus particles in the P3HR-1 Burkitt lymphoma cell line. Journal of Virology 41:1045-1051.

Kieff E, Liebowitz D (1990): Epstein-Barr virus and its replication. In Fields RN, Knipe DM (eds): "Virology," 2nd ed. New York: Raven Press, pp 1889-1920.

Lewin N, Aman P, Masucci MG, Klein E, Klein G, Öberg B, Strander $\mathrm{H}$, Henle W, Henle G (1987): Characterization of EBV-carrying
B-cell populations in healthy seropositive individuals with regard to density, release of transforming virus and spontaneous outgrowth. International Journal of Cancer 39:472-476.

Lewin N, Aman P, Mellstedt H, Zech L, Klein G (1988): Direct outgrowth of in vivo Epstein-Barr virus (EBV)-infected chronic lymphocytic leukemia (CLL) cells into permanent lines. International Journal of Cancer 41:892-895

Manthorpe R, Oxholm P, Prause JU, Schiodt M (1986): The Copenhagen criteria for Sjögren's syndrome. Scandinavian Journal of Rheumatology 61(Suppl):19-21.

Mariette X, Gozlan J, Clerc D, Bisson M, Morinet F (1991): Detection of Epstein-Barr virus DNA by in situ hybridization and polymerase chain reaction in salivary gland biopsy specimens from patients with Sjögren's syndrome. American Journal of Medicine 90:286-294.

Miller G, Robinson J, Heston L, Lipman M (1974): Differences between laboratory strains of Epstein-Barr virus based on immortalization, abortive infection, and interference. Proceedings of the National Academy of Science USA 71:4006-4010.

Miyasaka N, Yamaoka K, Tateishi M, Nishioka K, Yamamoto K (1989): Possible invovlement of Epstein-Barr virus (EBV) in polyclonal B-cell activation in Sjögren's syndrome. Journal of Autoimmunology 2:427-432.

Morgan DG, Niederman JC, Miller G, Smith HW (1979): Site of Epstein-Barr virus replication in the oropharynx. Lancet $2: 1154$ 1157.

Moutsopoulos HM, Chused TM, Mann DL, Klippel JH, Fauci AS, Frank MM, Lawley TJ, Hamburger MI (1980): Sjögren's syndrome (sicca syndrome): Current issues. Annals of Internal Medicine 92:212-226.

Niedobitek G, Young LS, Lau R, Brooks L, Greenspan D, Greenspan JS, Rickinson AB (1991): Epstein-Barr virus infection in oral hairy leukoplakia: Virus replication in the absence of a detectable latent phase. Journal of Genetic Virology 72:3035-3046.

Nilsson K, Klein G, Henle W, Henle G (1971): The establishment of lymphoblastoid cell lines from adult and from foetal human lymphoid tissue and its dependence on EBV. International Journal of Cancer 8:443-450.

Patton DF, Shirley P, Raab-Traub N, Resnick L, Sixbey JW (1988): Defective viral DNA in Epstein-Barr virus-associated oral hairy leukoplakia. Journal of Virology $64: 397-400$.

Rickinson AB, Young LS, Rowe M (1987): Influence of the EpsteinBarr nuclear antigen EBNA 2 on the growth phenotype of virustransformed B cells. Journal of Virology 61:1310-1317.

Rowe M, Young LS, Cadwallader K, Petti L, Kieff E, Rickinson AB (1989): Distinction between Epstein-Barr virus type A (EBNA 2A) and type B (EBNA 2B) isolates extends to the EBNA 3 family of nuclear proteins. Journal of Virology 63:1031-1039.

Rowe M, Young LS, Crocker J, Stokes H, Henderson S, Rickinson AB (1991): Epstein-Barr virus (EBV)-associated lymphoproliferative disease in the SCID mouse model: Implications for the pathogenesis of EBV-positive lymphomas in man. Journal of Experimental Medicine 173:147-158.

Saito I, Servenius B, Compton T, Fox RI (1989): Detection of EpsteinBarr virus DNA by polymerase chain reaction in blood and tissue biopsies from patients with Sjögren's syndrome. Journal of Experimental Medicine 169:2191-2198.

Schuurman HJ, Schemmann MHG, De Weger RA, Aanstoot H, Hene $R$ (1989): Epstein-Barr virus in the sublabial salivary gland in Sjogren's syndrome. American Journal of Clinical Pathology 91:461-463.

Sculley TB, Apolloni A, Hurren L, Moss DJ, Cooper DA (1990): Coinfection with A- and B-type Epstein-Barr virus in human immunodeficiency virus-positive subjects. Journal of Infectious Diseases 162:643-648

Sixbey JW, Nedrud JG, Raab-Traub N, Hanes RA, Pagano JS (1984): Epstein-Barr virus replication in oropharyngeal epithelial cells. New England Journal of Medicine 310:1225-1230.

Sixbey JW, Shirley P, Chesney PJ, Buntin DM, Resnick L (1989): Detection of a second widespread strain of Epstein-Barr virus. Lancet 2:761-765.

Sixbey JW, Shirley P, Sloas M, Raab-Traub N, Israele V (1991): A transformation-incompetent, nuclear antigen 2-deleted EpsteinBarr virus associated with replicative infection. Journal of Infectious Diseases 163:1008-1015.

Venables PJW, Teo CG, Baboonian C, Griffin BE, Hughes RA, Maini 
RN (1989): Persistence of Epstein-Barr virus in salivary gland biopsies from healthy individuals and patients with Sjögren's syndrome. Clinical Experiments in Immunology 75:359-364.

Yao QY, Rowe M, Martin B, Young LS, Rickinson AB (1991): The Epstein-Barr virus carrier state: Dominance of a single growthtransforming isolate in the blood and in the oropharynx of healthy virus carriers. Journal of Genetic Virology 72:1579-1590.
Young L, Alfieri C, Hennessy K, Evans H, O'Hara C, Anderson KC, Ritz J, Shapiro RS, Rickinson A, Kieff E, Cohen JI (1989): Expression of Epstein-Barr virus transformation-associated genes in tissues of patients with EBV lymphoproliferative disease. New England Journal of Medicine 321:1080-1085. 